\title{
Diagnosis to Treatment Interval and Outcome in Patients with Locally- Advanced Squamous Cell Carcinoma of the Head and Neck in a Veterans Affairs Medical Center
}

\author{
Brian T Brinkerhoff ${ }^{\prime \#}$, Nicholas W Choong ${ }^{2,3 \#}$, Becky L Massey ${ }^{3,4}$, Elizabeth M Gore ${ }^{3,5}$, Selim Y Firat ${ }^{3,5}$, Stuart J Wong ${ }^{2}$, Bruce H Campbell ${ }^{4}$, \\ Ralph M Schapira ${ }^{3}$, Alexis M Visotcky ${ }^{6}$ and Patrick M Tripp ${ }^{3,5}$ \\ \#Joint first authors \\ ${ }^{1}$ Medical College of Wisconsin, 8701 Watertown Plank Road, Milwaukee, WI 53226, USA \\ ${ }^{2}$ Division of Hematology and Oncology, Medical College of Wisconsin, 9200 W. Wisconsin Avenue, Milwaukee, WI 53226, USA \\ ${ }^{3}$ Clement J Zablocki Veterans Affairs Medical Center, 5000 W. National Avenue, Milwaukee, WI 53295, USA \\ ${ }^{4}$ Department of Otolaryngology and Communication Sciences, Medical College of Wisconsin, 9200 W. Wisconsin Avenue, Milwaukee, WI 53226, USA \\ ${ }^{5}$ Department of Radiation Oncology, Medical College of Wisconsin, 9200 W. Wisconsin Avenue, Milwaukee, WI53226, USA \\ ${ }^{6}$ Division of Biostatistics, Institute for Health and Society, Medical College of Wisconsin, 8701 Watertown Plank Road, Milwaukee, WI 53226, USA
}

\begin{abstract}
Background: Treatment of locally-advanced squamous cell carcinoma of the head and neck (SCCHN) requires multi-disciplinary care often resulting in a prolonged diagnosis to treatment interval (DTI). This study aims to identify factors that influence DTI and to assess the impact of DTI on treatment outcomes.
\end{abstract}

Methods: The medical records of 135 patients with SCCHN who were treated with definitive chemoradiotherapy between 2000 and 2009 at the Clement J Zablocki VA Medical Center were reviewed and analyzed.

Results: Median DTI was 44 days. A Cox-Model identified that transfer patients had prolonged DTI. Longer DTI had a significant negative impact on overall survival (RR 1.009, $p=0.0386)$ but did not impact distant ( RR $0.99, p$ $=0.89)$ or local control $(0.99, p=0.23)$.

Conclusion: Increased DTI in patients with SCCHN results in a statistically significant negative survival impact. Efforts need to be directed to improving DTI and on expediting and streamlining the care of transfer patients.

Keywords: Head and neck cancer; Chemotherapy; Radiotherapy; Treatment delay; Waiting time

\section{Introduction}

Locally-advanced stage squamous cell carcinoma of the head and neck (SCCHN) poses one of the most complex management challenges. This stage of disease is still potentially curable but requires carefully orchestrated combined-modality therapy. The staging and coordination of multiple different specialties can result in delay in initiation of therapy. Decreasing the diagnosis to treatment interval (DTI) in head and neck cancer patients is an important component of continuous quality improvement.

Reports analyzing the impact of the DTI on outcomes for patients with SCCHN have shown mixed results, with some showing negative impact of delay [1,2], and others showing no apparent change in tumor control regardless of the magnitude of delay [3]. But based on tumor repopulation and doubling time in SCCHN, biological models would predict worse outcome with longer DTI $[4,5]$.

SCCHN is a common malignancy in the Veterans Affairs (VA) healthcare system. The system includes 153 hospitals and 773 community-based outpatient clinics. Thirty-four of these hospitals have radiation oncology departments. The Milwaukee VA acts as the hub of specialized medical care and sees patients referred from outlying VA hospitals and clinics in Wisconsin, Northern Illinois and the Upper Peninsula of Michigan. Thus, inherent in this system is the potential for treatment delay as patients are transferred from one VA to another. We undertook this study at the Clement J Zablocki VA Medical Center in Milwaukee, WI to identify the factors that result in delay of treatment and to determine the impact of treatment delay on outcome.

\section{Methods}

After obtaining approval from the Institutional Review Board of the Clement J Zablocki VA Medical Center, the VA tumor registry was searched for patients with primary squamous cell carcinoma of the head and neck between 2000 and 2009. Data on patient demographics, clinical information, laboratory and pathologic characteristics were abstracted from the medical records, and all tumors were restaged according to the American Joint Committee on Cancer (AJCC) $7^{\text {th }}$ edition classification.

The DTI was defined as the number of days from biopsy to establish the diagnosis to start of treatment. The cohort includes patients treated using definitive concurrent radiation chemotherapy, and surgery was not included as part of definitive management. Induction chemotherapy was also not used in the cohort. Patients were referred to the Milwaukee VA Hospital from its own ENT service, and from medical oncology and ENT services at other VA hospitals and clinics within the region

*Corresponding author: Patrick M Tripp, M.D, Department of Radiation Oncology, Medical College of Wisconsin, 9200 W. Wisconsin Avenue, Milwaukee, WI53226 USA, Tel: 414-384-2000 (Ext: 42585); E-mail: PTripp@mcw.edu

Received March 22, 2012; Accepted May 15, 2012; Published May 17, 2012

Citation: Brinkerhoff BT, Choong NW, Massey BL, Gore EM, Firat SY, et al. (2012) Diagnosis to Treatment Interval and Outcome in Patients with Locally-Advanced Squamous Cell Carcinoma of the Head and Neck in a Veterans Affairs Medical Center. J Cancer Sci Ther 4: 111-115. doi:10.4172/1948-5956.1000122

Copyright: ( 2012 Brinkerhoff BT, et al. This is an open-access article distributed under the terms of the Creative Commons Attribution License, which permits unrestricted use, distribution, and reproduction in any medium, provided the original author and source are credited. 
Citation: Brinkerhoff BT, Choong NW, Massey BL, Gore EM, Firat SY, et al. (2012) Diagnosis to Treatment Interval and Outcome in Patients with Locally-Advanced Squamous Cell Carcinoma of the Head and Neck in a Veterans Affairs Medical Center. J Cancer Sci Ther 4: 111-115. doi:10.4172/1948-5956.1000122

of Wisconsin, Northern Illinois and the Upper Peninsula of Michigan, typically after a biopsy to establish the diagnosis was obtained.

Patients were included if they had a pathologically confirmed diagnosis of primary squamous cell carcinoma of the head and neck, had locally-advanced disease, and were recommended to have definitive concurrent chemoradiotherapy with curative intent. Locally-advanced stage squamous cell carcinoma of the head and neck was defined as AJCC stage III, IVA and IVB. Patients were excluded if they had a primary salivary gland tumor or primary cutaneous tumor. Patients were also excluded if concurrent chemoradiotherapy was given postoperatively. CT, physical exam and endoscopic findings were used for staging all the patients. Positron emission tomography (PET) was used for the majority of patients after 2006. Radiation treatment planning and delivery was done using 3-dimensional (3D) conformal and/or intensity-modulated radiation therapy (IMRT) techniques.

\section{Statistical considerations}

A Kaplan-Meier estimate of survival was used to analyze patient survival after diagnosis of SCCHN. The diagnosis to treatment interval (DTI) was calculated from the time of biopsy to establish pathologic diagnosis of SCCHN to initiation of therapy. Survival was estimated at the time from diagnosis of SCCHN to death, the last follow-up evaluation of those patients who were still alive or last contact. Cox proportional hazards functions were used to model the factors that impact diagnosis to treatment interval and to investigate the impact of diagnosis to treatment interval on survival and recurrence. The DTI was analyzed as a continuous variable in the Cox model.

\section{Results}

\section{Patient demographics}

Between 2000 and 2009, 490 patients with SCCHN were diagnosed and/or treated in the Clement J Zablocki VA Medical Center. Out of the 490 patients, 135 patients $(27.6 \%)$ were identified to have locallyadvanced head and neck cancer and treatment recommendation was definitive concurrent chemoradiotherapy. The other 355 patients were either early stage, not recommended for treatment with concurrent radiation chemotherapy, or treatment included induction chemotherapy or surgery. The study cohort was limited to patients with treatment recommendation for definitive concurrent chemoradiotherapy.

Patient demographics are listed in Table 1. Median age was 59.4 years ( $45-83$ years). Almost every patient was male (98.5\%). Smoking and heavy alcohol use was reported in $96.3 \%$ and $43.7 \%$, respectively. Fifty-six percent of patients lived locally while $43.7 \%$ were referred from outlying VA clinics and hospitals across the state of Wisconsin, Northern Illinois and the upper peninsula of Michigan. Karnofsky performance status was: $>90$ in 35 (25.9\%) patients, $>80$ in $49(36.2 \%)$ patients, and $\leq 80$ in $51(38.8 \%)$ patients.

Tumor stage at diagnosis was: stage II in $1(0.7 \%)$ patient, stage III in 33 (24.4\%) patients, stage IVA in 79 (58.5\%) patients, and stage IVB in $22(16.3 \%)$ patients. The one patient with stage II (T2N1M0) who received concurrent chemoradiotherapy had nasopharyngeal carcinoma, for which concurrent chemoradiotherapy was indicated. The most common tumor sites were oropharynx (57.0\%), larynx (28.9\%), and oral cavity (6.7\%). Thirty patients (22.2\%) required a gastrostomy-tube (G-tube) placement prior to initiation of therapy.

\section{Treatment for locally advanced head and neck cancer}

One hundred and thirty-three patients received concurrent chemoradiotherapy (Table 2). Two patients did not receive the initially planned concurrent chemotherapy because of newly identified metastatic disease (see below). The median radiotherapy dose delivered was $70 \mathrm{~Gy}(10.8-74.0 \mathrm{~Gy})$. 3D conformal and IMRT was used in 101 (75.9\%) and $26(19.5 \%)$ patients, respectively. The most commonly utilized chemotherapy regimens were high-dose cisplatin (63.2\%), weekly carboplatin-paclitaxel (13.5\%), and weekly cetuximab (6.8\%).

\section{Diagnosis to treatment interval}

The median interval from diagnosis of SCCHN to treatment was 44 days $(6-180)$. The majority of patients were treated within 20 to 60 days after establishing a diagnosis of cancer (Figure 1). Patients whose care was transferred from outlying VA community-based outpatient clinics and hospitals had a median diagnosis to treatment interval of 50 days (16-180 days) compared to 42 days ( $6-130$ days) for local patients $(\mathrm{p}=0.0103)$.

\begin{tabular}{|c|c|c|}
\hline Characteristic & $\mathrm{N}=135$ & \\
\hline \multicolumn{3}{|l|}{ Median age 59.4 years ( $45-83$ years) } \\
\hline $\begin{array}{l}\text { Sex } \\
\text { Male } \\
\text { Female }\end{array}$ & $\begin{array}{c}133 \\
2\end{array}$ & $\begin{array}{c}98.5 \% \\
1.5 \%\end{array}$ \\
\hline $\begin{array}{l}\text { Patient location } \\
\text { Local } \\
\text { Transfer }\end{array}$ & $\begin{array}{l}76 \\
59\end{array}$ & $\begin{array}{l}56.2 \% \\
43.7 \%\end{array}$ \\
\hline $\begin{array}{l}\text { Distance from medical center } \\
\text { Mean } \\
\text { Median }\end{array}$ & $\begin{array}{l}134 \text { miles } \\
95 \text { miles }\end{array}$ & (2 - 1959 miles) \\
\hline $\begin{array}{l}\text { Karnofsky performance statuses } \\
\text { Below } 70 \\
71-80 \\
81-90 \\
91-100\end{array}$ & $\begin{array}{l}27 \\
24 \\
49 \\
35\end{array}$ & $\begin{array}{l}20.0 \% \\
17.8 \% \\
36.2 \% \\
25.9 \%\end{array}$ \\
\hline $\begin{array}{l}\text { Stage at diagnosis } \\
\text { Stage II } \\
\text { Stage III } \\
\text { Stage IVA } \\
\text { Stage IVB }\end{array}$ & $\begin{array}{c}1 \\
33 \\
79 \\
22\end{array}$ & $\begin{array}{l}0.7 \% \\
24.4 \% \\
58.5 \% \\
16.3 \%\end{array}$ \\
\hline $\begin{array}{l}\text { Primary tumor site } \\
\text { Oropharynx } \\
\text { Larynx } \\
\text { Oral cavity } \\
\text { Nasopharynx } \\
\text { Hypopharynx }\end{array}$ & $\begin{array}{c}77 \\
39 \\
9 \\
6 \\
4\end{array}$ & $\begin{array}{c}57.0 \% \\
28.9 \% \\
6.7 \% \\
4.4 \% \\
3.0 \%\end{array}$ \\
\hline
\end{tabular}

Table 1: Patient demographics.

\begin{tabular}{|l|c|c|}
\hline Treatment modality & $\mathbf{n}$ & $\%$ \\
\hline Median radiotherapy dose 70 Gy (10.8-74.0 Gy) & \\
\hline Radiation technique & 26 & $19.5 \%$ \\
Intensity modulated radiotherapy (IMRT) & 101 & $75.9 \%$ \\
3-dimensional conformal radiotherapy (3D) & 6 & $4.5 \%$ \\
3D and IMRT combined & & \\
\hline Chemotherapy & 84 & $63.2 \%$ \\
Cisplatin & 18 & $13.5 \%$ \\
Carboplatin + Paclitaxel & 9 & $6.8 \%$ \\
Cetuximab & 5 & $3.8 \%$ \\
Carboplatin + 5-Flurouracil & 5 & $3.8 \%$ \\
Cisplatin + Cetuximab & 4 & $3.0 \%$ \\
Paclitaxel & 3 & $2.3 \%$ \\
Carboplatin & 2 & $1.5 \%$ \\
Cisplatin + Paclitaxel & 1 & $0.8 \%$ \\
Cisplatin + 5-Flurouracil & 1 & $0.8 \%$ \\
Gemcitabine & 1 & $0.8 \%$ \\
5-Flurouracil & & \\
\hline
\end{tabular}

Table 2: Treatment received. 
Citation: Brinkerhoff BT, Choong NW, Massey BL, Gore EM, Firat SY, et al. (2012) Diagnosis to Treatment Interval and Outcome in Patients with Locally-Advanced Squamous Cell Carcinoma of the Head and Neck in a Veterans Affairs Medical Center. J Cancer Sci Ther 4: 111-115. doi:10.4172/1948-5956.1000122

A Cox-Model was utilized to evaluate factors that influence the diagnosis to treatment interval. Variables initially included into the model were: KPS, tumor stage, age, transfer from other centers, tumor site, radiation technique, and pre-treatment G-tube placement. After stepwise selection into the model, the only significant predictor of prolonged diagnosis to treatment interval was transfer of care from other centers (Table 3). There was no significant interaction effect.

\section{Outcome of treatment delay}

One hundred and thirty-five (135) patients were originally identified to have locally-advanced SCCHN and were recommended to undergo definitive concurrent chemoradiotherapy with curative intent. Between the time from diagnostic biopsy to initiation of treatment, 2 patients with SCCHN were "up-staged" from their initial stage of T4N3M0 and T3N3M0. Both these patients had appropriate chest imaging as part of their staging evaluation but were found to have developed lung and mediastinal lymph node metastases on the pretreatment radiotherapy simulation CT scan. Times from diagnosis to development of lung metastases in these patients were 27 and 65 days, respectively. Both these patients received only palliative radiotherapy.

The median follow-up of our patients was 2 years $(0.2-10$ years). Overall survival of patients with stage III, IVA and IVB is depicted in Figure 2. Median survival for stage II was not reached. The median survival times for stage III, IVA, and IVB were 3.6 years, 3.8 years, and 1.2 years respectively.

When survival distribution was estimated to assess the impact of treatment delay on overall survival, we found that incremental increases in the diagnosis to treatment interval resulted in a significant impact on overall survival (RR 1.009, 95\% CI, 1.000-1.017, $\mathrm{p}=0.0386$ ) (Table 4).

A total of 54 tumor relapses were identified. Local-regional tumor relapse occurred in 31 patients $(23.0 \%)$ and distant recurrence/ metastases occurred in 36 patients (26.7\%). The cumulative incidence was utilized to assess the impact of treatment delay on local (RR 0.99,

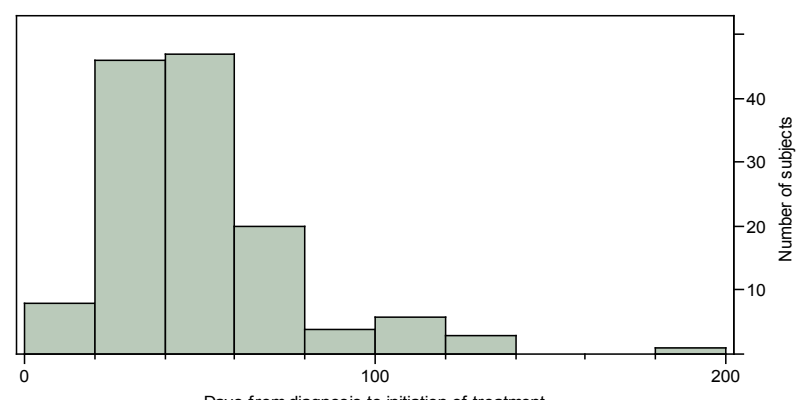

Figure 1: Diagnosis to treatment interval.

\begin{tabular}{|l|c|c|c|c|}
\hline Effect & $\mathbf{n}$ & Relative Risk & $\mathbf{9 5 \%} \mathbf{C l}$ & p-value \\
\hline Transfer & & & & \\
\hline Local patients & 76 & 1.0 & & \\
\hline $\begin{array}{l}\text { Transferred from other } \\
\text { facilities }\end{array}$ & 59 & 0.628 & $\begin{array}{c}0.44, \\
0.91)\end{array}$ & 0.0130 \\
\hline
\end{tabular}

Table 3: Cox-Model for factors that increase diagnosis to treatment interval.

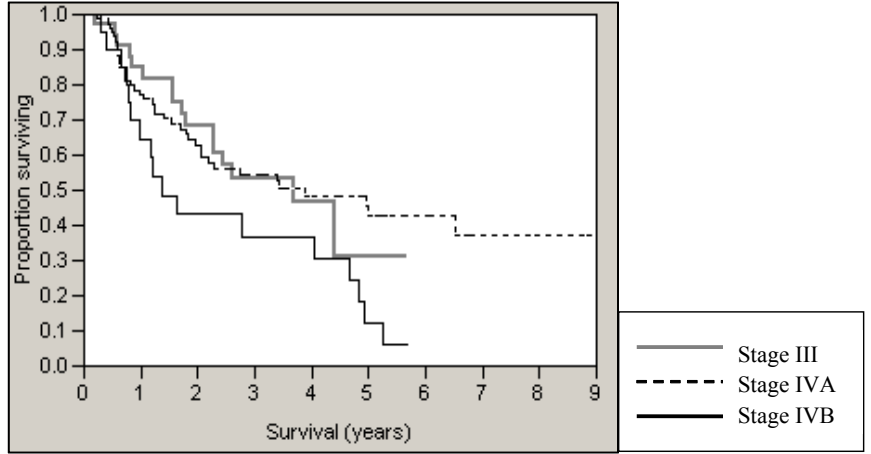

* Survival of patients with Stage II not shown

Figure 2: Overall survival of patient with locally advanced SCCHN by disease stage.

\begin{tabular}{|l|c|c|c|c|}
\hline Patient outcome & $\mathbf{n}$ & Relative Risk & $\mathbf{9 5 \%} \mathbf{C l}$ & $\mathbf{p}$-value \\
\hline Overall survival & 135 & 1.009 & $(1.000,1.017)$ & 0.0386 \\
\hline Local recurrence & 135 & 0.99 & $(0.974,1.006)$ & 0.225 \\
\hline Distant metastasis & 135 & 0.999 & $(0.985,1.013)$ & 0.8949 \\
\hline
\end{tabular}

Table 4: Impact of treatment delay on overall survival, local and distant metastasis.

95\% CI, 0.974-1.006, $\mathrm{p}=0.225)$ and distant recurrences (RR 0.999, 95\% CI, 0.985-1.013, $\mathrm{p}=0.8949$ ) (Table 4).

\section{Discussion}

Our retrospective study evaluated the factors that increased the DTI for patients with SCCHN undergoing concurrent chemoradiotherapy and its impact on treatment outcomes. The median DTI of 44 days was comparable to results reported in other series. Two patients staged at diagnosis to have potentially curable disease had metastases identified while waiting to start treatment. However, both these patients had advanced T-stage and $\mathrm{N}$-stage, which is associated with high likelihood of distant metastases [6-8]. The impact of treatment delay in both these patients is unclear given their advanced stage of disease at presentation and the possibility that at presentation these patients already had metastatic disease below the threshold of detection by current imaging standards.

The Cox-Model identified that the only significant predictor of prolonged diagnosis to treatment interval was being a patient whose treatment plan required transfer of care to our VA Medical Center from facilities such as another VA hospital or VA community-based outpatient clinic.

\section{Particular concerns for VA patients}

It is likely that both the VA medical infrastructure and individual patient factors contribute to the delay identified in our study. Better appointment coordination between the various treating disciplines and facilities will likely reduce the DTI; however, navigating a complex infrastructure is daunting even in the best of circumstances and is particularly problematic in a patient population that is frequently faced with financial and psychosocial limitations in addition to the physical and psychological impact of a recent cancer diagnosis. Transportation poses a unique and major problem for this population. Many patients do not have their own transportation, and travel using VA-supplied 
Citation: Brinkerhoff BT, Choong NW, Massey BL, Gore EM, Firat SY, et al. (2012) Diagnosis to Treatment Interval and Outcome in Patients with Locally-Advanced Squamous Cell Carcinoma of the Head and Neck in a Veterans Affairs Medical Center. J Cancer Sci Ther 4: 111-115. doi:10.4172/1948-5956.1000122

transportation can take our patients up to two days to get to the medical center. In addition, our patients, many of whom are selfemployed or daily-wage workers, often have work, financial or personal commitments that require management or rearrangement before the patients can commit to prolonged stays in a distant city for treatment.

\section{Radiation oncology facility density in the patient cohort geographic area}

Locations of radiation oncology facilities have been surveyed as a rough guide to patient access to care. In the most recently updated assessment of radiation oncology facilities, Wisconsin has 1.91 facilities per 1,000 estimated cancer cases per year, Illinois has 1.78 and Michigan has 1.31 facilities. The mean number of facilities per state per 1,000 cancer cases is 1.69 [9]. While instructive, this guide is likely not representative for patients treated within the VA. Thirtyfour VA hospitals have radiation oncology services on site, and VA hospitals without radiation oncology departments typically send patients to nearby medical schools or community radiation centers. The Milwaukee VA serves as a hub of specialized medical care for patients in a widespread catchment area including all of Wisconsin and parts of Illinois and Michigan, and the Milwaukee VA Radiation Oncology Department is the region's designated radiation treatment referral center. But typically patients in this area do not choose their treatment facility, and instead these patients from outlying hospitals and clinics within the region are referred to the Milwaukee VA as the region's designated radiation oncology center.

\section{Explanation of outcome}

We identified a statistically significant detriment in overall survival with treatment delay. The apparent decreased overall survival does not appear to be a result of poor local or distant control. One hypothesis we considered is that patients with longer treatment delays have increased

\begin{tabular}{|c|c|c|c|c|}
\hline Author (year) & $\begin{array}{l}\text { Number of } \\
\text { patients }\end{array}$ & $\begin{array}{l}\text { Median } \\
\text { DTI }\end{array}$ & $\begin{array}{l}\text { Outcomes } \\
\text { measured }\end{array}$ & Finding \\
\hline $\begin{array}{l}\text { Caudell et al. [3] } \\
\text { in } 2011\end{array}$ & 426 & 34 days & LRC, OS & $\begin{array}{l}\text { No significant } \\
\text { differences }\end{array}$ \\
\hline $\begin{array}{l}\text { Jensen et al. [1] } \\
\text { in } 2007\end{array}$ & 61 & 28 days $^{*}$ & $\begin{array}{l}\text { TV, TVD, } \\
\text { TNM, } \\
\text { RECIST }\end{array}$ & $\begin{array}{l}\text { Majority of patients } \\
\text { showed significant } \\
\text { signs of tumor } \\
\text { progression }\end{array}$ \\
\hline $\begin{array}{l}\text { Waaijer et al. [2] } \\
\text { in } 2003\end{array}$ & 13 & 56 days & TCP & Tumor progression \\
\hline $\begin{array}{l}\text { Brouha et al. [9] } \\
\text { in } 2000\end{array}$ & $\begin{array}{l}362 \\
\text { all T1N0 } \\
\text { larynx }\end{array}$ & 43 days & LRC & No effect \\
\hline $\begin{array}{l}\text { Hansen et al. } \\
{[10] \text { in } 2005}\end{array}$ & $\begin{array}{c}544 \text { all } \\
\text { larynx } \\
\text { stages I-III }\end{array}$ & & 5-year RFS & $\begin{array}{l}\text { Worse RFS } 1.045 \\
\text { hazard ratio }\end{array}$ \\
\hline $\begin{array}{c}\text { This study: } \\
\text { Brinkerhoff et al. } \\
\text { [12] } 2010\end{array}$ & 135 & 44 days & LRC, OS & $\begin{array}{l}\text { Significant difference } \\
\text { on OS }\end{array}$ \\
\hline
\end{tabular}

*This study measured the interval between neck diagnostic CT scan and radiation treatment planning CT scan

LRC: Local Regional Control; OS: Overall Survival; TV: Tumor Volume Increase TVD: Tumor Volume Doubling time; TNM: TNM Stage Classification; RECIST: RECIST Criteria for Progressive Disease; TCP: Tumor Control Probability Model; RFS: Recurrence Free Survival

Table 5: Other studies examining DTI in SCCHN. treatment-related morbidity and subsequent risk of death because of declining overall health while awaiting treatment. Another explanation may be merely that our cohort was not large enough to detect small differences in tumor control.

\section{Other reported experiences}

Several retrospective studies have measured the impact of delay to radiation treatment on tumor control [1-3,10,11] (Table 5). A study from the University of Alabama at Birmingham which included 427 patients with stages III and IV SCCHN (307 received concurrent chemoradiotherapy) measured median DTI at 34 days (7 - 441 days). This study did not find differences in local control, distant metastasis, or overall survival as a result of increased DTI [3]. A study from the Netherlands analyzing only patients with T1N0 larynx cancers found median waiting time 43 days, and did not find significant correlation between waiting time and outcome [10]. Delays in DTI for patients with early-stage larynx cancer may not have the same impact as delays for patients with lymph node-positive head and neck cancer, but interestingly, in a patient population that required no coordination of care with other services and limited pretreatment testing and uncomplicated radiation planning, the DTI was very similar to what we found in our patient population.

However, other investigators have found negative outcomes from such delays. Investigators at Aarhus University Hospital in Denmark compared tumor measurements on neck diagnostic CT scans against the radiation treatment planning CT scans and identified new neck lymphadenopathy in $20 \%$ of patients at the time of radiation planning [1]. In line with this, a group from the Netherlands showed that a tumor, on average, could have a $70 \%$ increase in volume over a waiting period of 56 days for oropharyngeal cancers [2]. A study of 611 patients with stages I - III larynx cancer treated using radiation alone in Denmark from 1965 - 1997 found decrease in recurrence-free survival with increased time to treatment [11]. Biological modeling that accounts for tumor stem cells, tumor doubling time, surviving fraction and the effect of delay lend support that at some point in the progression of the disease, the chances of tumor control will decrease dramatically [4]. The probability of metastases and death from head and neck cancer increases as a continuous variable over time.

\section{Limitations of the study}

One limitation of all reported studies, including ours, may be sample size. Given reported experience showing that at least some patients have disease progression in the DTI $[1,2]$ and given that outcomes are worse with larger volume and higher stage disease, small cohorts such as ours and other reported series may not be able to detect small but measurable differences in outcome with changes in DTI.

Other factors that may significantly impact on tolerance to concurrent chemoradiotherapy which are not well measured in retrospective series include (1) organ dysfunction relative to DTI, (2) risk of increased toxicity from radiation treatment with larger radiation treatment volumes and (3) increased risk of weight loss prior to treatment.

One other possible time-point to measure of DTI is to determine the date of initial symptom or date when the tumor was identified on examination. These measures might present a more comprehensive view of patient care in the VA health system. But such measures, especially in a retrospective setting, are inaccurate or unavailable. 
Citation: Brinkerhoff BT, Choong NW, Massey BL, Gore EM, Firat SY, et al. (2012) Diagnosis to Treatment Interval and Outcome in Patients with Locally-Advanced Squamous Cell Carcinoma of the Head and Neck in a Veterans Affairs Medical Center. J Cancer Sci Ther 4: 111-115. doi:10.4172/1948-5956.1000122

\section{Contributions of this study}

Given the heterogeneity of the aforementioned studies, our study stands out despite being a retrospective review. Strengths of this study include: almost all patients were male veterans treated at a single VA medical center, most patients had risk-factors of smoking and heavy alcohol use, and every patient received concurrent chemoradiotherapy. Because patients were treated at a VA medical center, the influence of $3^{\text {rd }}$-party private insurance payers was negligible. HPV status was not accounted for in our study. Almost all our patients reported a significant smoking history or alcohol use, reducing the chances of HPV-induced tumors. To our knowledge, this is the only study that measured the diagnosis to treatment interval in a cohort of SCCHN patients all treated using concurrent chemotherapy.

Timeliness of care and prompt access to specialists has been an important issue throughout the VA and identified as a high priority VA performance measure. Recently, our Head and Neck Oncology multidisciplinary group participated in the national Veterans Health Administration Phase II Cancer Care Collaborative to develop initiatives to improve the timeliness and quality of cancer care throughout the VA health care system. With lessons from the Collaborative, our group has started prospectively collecting data on DTI, and the head and neck surgery, radiation oncology and medical oncology services briefly meet twice a month for real-time data review and recommendations for improvements. This will hopefully lead to improved timeliness of care in our veterans.

\section{Conclusions}

Increased diagnosis to treatment interval in patients with SCCHN results in a statistically significant negative survival impact. Efforts need to be directed to improving the diagnosis to treatment interval, and in the VA patient population, should initially focus on expediting and streamlining the transfer of patient care.

\section{Conflict of Interest}

We have no conflict of interest to disclose in this study.

\section{Acknowledgement}

Supported, in part, by grant 1 UL1RR031973 from the Clinical and Translational
Science Award (CTSA) program of the National Center for Research Resources National Institute of Health.

\section{References}

1. Jensen AR, Nellemann HM, Overgaard J (2007) Tumor progression in waiting time for radiotherapy in head and neck cancer. Radiother Oncol 84: 5-10.

2. Waaijer A, Terhaard CH, Dehnad H, Hordijk GJ, van Leeuwen MS, et al. (2003) Waiting times for radiotherapy: consequences of volume increase for the TCP in oropharyngeal carcinoma. Radiother Oncol 66: 271-276.

3. Caudell JJ, Locher JL, Bonner JA (2011) Diagnosis-to-treatment interval and control of locoregionally advanced head and neck cancer. Arch Otolaryngol Head Neck Surg 137: 282-285

4. Mackillop WJ, Bates JH, O'Sullivan B, Withers HR (1996) The effect of delay in treatment on local control by radiotherapy. Int J Radiat Oncol Biol Phys 34: 243-250.

5. Wyatt RM, Beddoe AH, Dale RG (2003) The effects of delays in radiotherapy treatment on tumour control. Phys Med Biol 48: 139-55.

6. Alvi A, Johnson JT (1997) Development of distant metastasis after treatment of advanced-stage head and neck cancer. Head Neck 19: 500-505.

7. Garavello W, Ciardo A, Spreafico R, Gaini RM (2006) Risk factors for distant metastases in head and neck squamous cell carcinoma. Arch Otolaryngo Head Neck Surg 132: 762-766.

8. Li X, Di B, Shang Y, Zhou Y, Cheng J, et al. (2009) Clinicopathologic risk factors for distant metastases from head and neck squamous cell carcinomas. Eur $J$ Surg Oncol 35: 1348-1353.

9. Ballas LK, Elkin EB, Schrag D, Minsky BD, Bach PB (2006) Radiation therapy facilities in the United States. Int J Radiat Oncol Biol Phys 66: 1204-1211.

10. Brouha XD, Op De Coul B, Terhaard CH, Hordijk GJ (2000) Does waiting time for radiotherapy affect local control of T1NOM0 glottic laryngeal carcinoma? Clin Otolaryngol Allied Sci 25: 215-218.

11. Hansen O, Larsen S, Bastholt L, Godballe C, Jørgensen KE (2005) Duration of symptoms: impact on outcome of radiotherapy in glottic cancer patients. Int $J$ Radiat Oncol Biol Phys 61: 789-794.

12. Brinkerhoff BT, Choong NW, Massey BL (2010) Diagnosis to Treatment Interva and Outcome in Patients with Locally-Advanced Squamous Cell Carcinoma of the Head and Neck in a Veterans Affairs Medical Center. Astro Multidisciplinary Head and Neck Cancer Symposium, Chandler, Ariz. 